\title{
The First Study on Nuclear Polyhedrosis Virus Histopathological and Morphological Effects on the Strawberry Pest, Pentodon Algerinum (coleoptera: Scarabaeidae)
}

Samah, M.M. Abd El-Aziz, Magda, H. Rady, Bouthaina, A. Merdan, Abd El-Salam, A.M.E, Hany, M. Hussein \& El-Sayed, M.A. El-Saiedy

National Research Centre \& Ainshams University

\section{ABSTRACT}

In Egypt, strawberry is an economically important crop that has recently been destroyed by Pentodon algerinum, a worldwide polyphagous destructive insect pest. This study aimed to distinguish, for the first time, the histopathological and morphological effects of Spodoptera littoralis Nuclear polyhedrosis virus (SpliNPV) and Pentodon algerinum Nuclear polyhedrosis virus (PNPV) on Pentodon algerinum third instar larvae to confirm their success as safe alternative control agents against this pest. The results showed that PNPV and SpliNPV affected Pentodon larvae by the same effects in causing the following: integument deformation and rupture; the destruction of the hypodermal layer resulting in the inhibition of the process of molting into the pupa stage, reducing pest survival; larva leg corrosion, which prevents its spreading; the rupture of fat bodies, which leads to the loss of stored energetic materials; the distortion of muscle sarcolemma and fibers resulting in weakness and softness; the tracheal cuticular layer destruction, which inhibits breathing; midgut rupture with cells detaching from each other; irregular cytoplasm distribution; the loss of the columnar shape of cells; the appearance of vacuoles between cells, which results in their inability to feed or to digest; the swelling, softness, liquefaction, and, lastly, death of the larva.

Keywords: pentodon algerinum, nuclear polyhedrosis virus, pnpv, splinpv, histopathology, morphology.

Classification: For Code: 069999

Language: English

London

Journals Press
LJP Copyright ID: 925648

Print ISSN: 2631-8490

Online ISSN: 2631-8504

London Journal of Research in Science: Natural and Formal 



\title{
The First Study on Nuclear Polyhedrosis Virus Histopathological and Morphological Effects on the Strawberry Pest, Pentodon Algerinum (coleoptera: Scarabaeidae)
}

\author{
Samah, M.M. Abd El-Aziz ${ }^{*}$, Magda, H. Rady ${ }^{\sigma}$, Bouthaina, A. Merdan ${ }^{\rho}$, Abd El-Salam, A.M.E ${ }^{\omega}$, \\ Hany, M. Hussein ${ }^{*} \&$ El-Sayed, M.A. El-Saiedy ${ }^{\S}$
}

\section{ABSTRACT}

In Egypt, strawberry is an economically important crop that has recently been destroyed by Pentodon algerinum, a worldwide polyphagous destructive insect pest. This study aimed to distinguish, for the first time, the histopathological and morphological effects of Spodoptera littoralis Nuclear polyhedrosis virus (SpliNPV) and Pentodon algerinum Nuclear polyhedrosis virus (PNPV) on Pentodon algerinum third instar larvae to confirm their success as safe alternative control agents against this pest. The results showed that PNPV and SpliNPV affected Pentodon larvae by the same effects in causing the following: integument deformation and rupture; the destruction of the hypodermal layer resulting in the inhibition of the process of molting into the pupa stage, reducing pest survival; larva leg corrosion, which prevents its spreading; the rupture of fat bodies, which leads to the loss of stored energetic materials; the distortion of muscle sarcolemma and fibers resulting in weakness and softness; the tracheal cuticular layer destruction, which inhibits breathing; midgut rupture with cells detaching from each other; irregular cytoplasm distribution; the loss of the columnar shape of cells; the appearance of vacuoles between cells, which results in their inability to feed or to digest; the swelling, softness, liquefaction, and, lastly, death of the larva. Thus, PNPV and SpliNPV were effective against the Pentodon larva and caused various physiological changes that disrupted its normal functions, leading to the collapse of its population. Hence, PNPV and SpliNPV can be recommended as eco-friendly safe alternative biological control agents against Pentodon algerinum.

Keywords: pentodon algerinum, nuclear polyhedrosis virus, pnpv, splinpv, histopathology, morphology.

Author $a \omega ¥ \S$ : Pests \& Plant Protection Department, National Research Centre \& Ainshams University, Dokki, Giza, Egypt.

$\sigma$ p: Department of Entomology, Faculty of Science, AinShams University, Cairo, Egypt.

\section{INTRODUCTION}

The strawberry (Fragaria ananassa) is of high nutritional value and great economic importance. (Francesca et al., 2012). In 2014, Egypt ranked $4^{\text {th }}$ globally in the quantity and quality of strawberry production. (FAO, 2016). Furthermore, in 2016-2019, Egypt ranked $6^{\text {th }}$ among the top 10 producers of strawberries worldwide (FAOSTAT, 2021).

Pentodon algerinum is a ubiquitous agricultural polyphagous insect pest that has recently been destroying strawberry in Egypt. Pentodon larvae are known as the waste organic manure larvae (White grubs).The larva has a brown head and a thick large arched yellowish body (Abd El-Salam, 2019; Ramadan and Mahmoud, 2021). The larvae live in sandy soil around the roots of plants in a curved shape, forming the letter "C," and feed on organic matter and plant roots or tubers, causing the plant to wilt and die rapidly (Abd El-Salam 2019; Samah et al., 2021).

The use of chemical pesticides causes health problems to humans, toxicity to domestic animals 
and beneficial insects, also causes resistant insect development to traditional pesticides and increases environmental pollution (Abd El-Salam et al., 2013; Parra, 2014). As such, there is a strong need to find alternative pesticides for insect pest control such as entomopathogenic baculoviruses (Samah et al., 2019, 2021).

The development of baculoviruses (including nuclear polyhedrosis virus) as biological insecticides is required for maintaining food safety and ecological security (Zhao et al., 2019; Abid et al., 2020a, 2020b; Qayyum et al., 2020; Wilson et al., 2020; Yasin et al., 2020).

Baculovirus cannot infect humans because it needs an alkaline-based cell structure to replicate itself, whereas the human cell structure is acidic-based. Also, it requires complementing with its specific receptor sequence on the insect target cell surface for its entry to initiate infection. This receptor is not found in humans. Virus receptor complementing is too specific on both the species and the cell type infected by a given virus. Therefore, baculoviruses are safe alternative biological insect pest control agents such as Nuclear Polyhedrosis Virus (NPV) by virtue of their having double-stranded DNA and being highly specific to their host insects (Salama et al., 2017; Samah et al., 2019, 2021; Masson et al., 2021).

Baculoviruses block molting and interfere with normal development, causing a weak expression of the ecdysteroid UDP (Uridine diphosphate) glucosyltransferase gene that encodes the ecdysteroid UDP-glucosyltransferase enzyme, which induces the transfer of glucose from UDP-glucose to ecdysteroids, insect molting hormones (O’Reilly, 1995).

Studies on the histopathological effect of the Zetheniaru fescentaria Nuclear Polyhedrosis Virus (ZrNPV) on the Zetheniaru fescentaria Motsch larvae have confirmed that ZrNPV multiplies within the nuclei of epidermal cells, fat bodies, blood cells, the tracheal matrix, and midgut cells, destroying them in the process (Daibin et al., 1999).
Histopathological studies on the effects of the Diaphania pulverulentalis Nuclear Polyhedrosis Virus (DpNPV) on $D p$ larvae have revealed that the midgut infected by $N P V$ was characterized by hypertrophy of virions-filled nuclei and, therefore, the death of leaf Webber larvae (Pachiappan et al., 2018).

This study aimed to distinguish, for the first time, the histopathological and morphological effects of Spodoptera littoralis Nuclear polyhedrosis virus (SpliNPV) and Pentodon algerinum Nuclear polyhedrosis virus (PNPV) on Pentodon algerinum third instar larvae to confirm their efficacy as eco-friendly safe alternative biological control agents against Pentodon algerinum.

\section{MATERIALS AND METHODS}

\subsection{Production and isolation of Nuclear Polyhedrosis virus}

The original Nuclear Polyhedrosis virus (NPV) types were produced and isolated from infected Spodoptera littoralis larvae as SpliNPV and from infected Pentodon algerinum larvae as PNPV by Samah M.M. Abd EL-Aziz (Salama et al., 2017; Samah et al., 2019, 2021) at the laboratory of Pests \& Plant Protection Department, National Research Centre, Egypt, and stored at $-20^{\circ} \mathrm{C}$ till use.

\subsection{The Histopathological and Morphological investigations of the effects of PNPV and Spli NPV on the Strawberry pest. Pentodon algerinum}

Third instar larvae infected by $P N P V$ and SpliNPV were investigated histopathologically and morphologically until death.

2.2.1 The histopathological investigation was made according to (Prophet et al., 1992) as follows

Tissue processing, which entails dehydration, clearing, and infiltration, took 3-4hours.

The sample was rinsed briefly in running water, with the passage of the sample through ethyl alcohol (80\%) if necessary, followed by its passage through Ethyl alcohol (95\%) for three time changes (15-20minutes per time change), 
followed by its passage through pure ethyl alcohol for 15minutes, through equal portions of absolute ethyl alcohol and xylene for 15minutes, through Xylene for two time changes (15minutes per time change), through paraffin for three time changes (15minutes per time change), through paraffin in a vacuum for 15-20minutes, and then embedding.

The fixation by Harris' hematoxylin and Eosin procedures took a maximum of three hours:

Fixation: In Bouin's or Zenker's solution (10\% buffered neutral formalin).

Sections: Paraffin, frozen or celloidin, 3-2omicrometers.

Solutions: Acid alcohol (1\%), Ammonia water, saturated Lithium carbonate, Eosin-Phloxine solution, Harris' hematoxylin (5g of hematoxylin, $50 \mathrm{ml}$ of ethyl alcohol (100\%), $100 \mathrm{~g}$ of potassium or ammonium, alum, 1000ml distilled water, and $2.5 \mathrm{~g}$ of mercuric oxide, red).

Slides are Deparafinized and dehydrated to distilled water with Dezenkerizing (if necessary) before staining, followed by staining in freshly filtered Harris' hematoxylin for 6-15 minutes, then Washing in running tap water for 2-15minutes, differentiating in acid alcohol (1\%) with 1-2dips, then washing briefly in tap water, placing in weak ammonia water or saturated lithium carbonate solution until the sections are bright blue, washing thoroughly in running tap water for 10minutes, placing in ethyl alcohol (80\%) for 1-2minutes, counterstaining in Eosin-Phloxine solution for 2minutes, dehydrating and clearing through two changes, each of ethyl alcohol (95\%), absolute ethyl alcohol, and xylene (2minutes each), and then mounting with resinous media.

The slides were investigated and photographed under a light microscope.

\subsubsection{Morphological investigation}

Morphological investigation was carried out by recording and photographing any malformation noticed after infection till death.

\section{RESULTS}

This study revealed that $P N P V$ and SpliNPV had the same histopathological and morphological effects on this pest larva.

\subsection{Histopathology of NPV- infected Pentodon larva integument}

The infected larva integument appeared filled with NPV viral particles. Also, it was deformed and ruptured compared with the healthy larva, leading to leg corrosion as morphological malformation (Figs. 12a, b, c, d, e, f) compared to the normal larva (Figs. 11a, b), preventing this pest from spreading. The destruction of the hypodermal layer was also observed. Furthermore, the irregular shape of the cuticular layer and its detachment from the underlying hypodermal layer was recorded (Figs. 2a, b, c, d, e) compared with normal integument (Figs. 1a, b, c). The destruction of the hypodermal layer led to the inhibition of the process of molting to the pupa stage; therefore, the rate of survival of this pest was reduced. On the other hand, normal $P$. algerinum larvae molted to the pupa stage, then to the adult stage (Figs. 11c, d).

\subsection{Histopathology of NPV-infected fat bodies}

The infected larva fat bodies lost both adipocytes \& fusion of lobules, leading to the collapse of the lobular architecture. They lost waste granules and they were filled with viral particles. Also, there was shrinkage of the fat bodies with vacuoles between cells with unclear nuclei and rupture of the cell sheath (Figs. 4a, b, c, d, e, f, g) compared with normal fat bodies (Figs. 3a, b, c, d, e); therefore, energy reserves were lost, leading to the dryness of the infected larva as a morphological symptom (Fig. 12g, h, i) compared to the normal larva (Figs. 11a, b).

\subsection{Histopathology of NPV-infected larval muscles.}

The infected larval muscles were filled with NPV and appeared with irregular shapes of sarcolemma with fissure-like appearances. The fibers were also distorted and not compacted (Figs. 6a, b, c, d, e) compared with normal muscles (Figs. 5a, b). Thus, weakness and softness 
were the resulting morphological symptoms (Fig. 12a, b, c, d, e, f, g, h, i) in the infected larvae compared to normal larvae (Figs. 11a, b).

\subsection{Histopathology of the NPV-infected Pentodon larva's tracheal matrix}

The infected larva's tracheal matrix was filled with Nuclear Polyhedrosis virus, also had a crushed cuticle layer and acute necrosis around it (Figs. $8 \mathrm{a}, \mathrm{b}, \mathrm{c}, \mathrm{d})$ compared with the normal tracheal matrix (Figs. 7a, b). Therefore, the inability to breathe occurred as a result.

\subsection{Histopathology of the NPV-infected Pentodon larva's gut region}

The infected larva's gut region was filled with viral particles and appeared with no distinguishing of any cells. Also, the midgut was destroyed with the detachment of cells from each other, the irregular distribution of the cytoplasm, cells losing of their columnar shape, and the appearance of vacuoles between cells (Figs. 10a, b, c, d) compared with the normal midgut (Figs. 9a, b, c). All these caused the inability of NPV-infected larva to feed or to digest, which leads to swelling, softness, and liquefaction as morphological effects caused by the virus (Figs. 12j) compared to the normal larvae (Figs. 11a, b). All these culminate in the death of the infected larvae.

\subsection{Morphological investigation}

Morphological investigation revealed that $P N P V$ and SpliNPV infection had the same signs and symptoms, including corrosion of the legs of the larva, which decreases its spreading and causes dryness, weakness, swelling, softness, liquefaction, bursting, and, finally, the death of these larvae. Also, the process of molting to the pupa stage was inhibited, leading to the interruption of the life cycle of this pest, which represents impairment in the survival of the species. A comparison of the interrupted life cycle to the normal life cycle of the larva is seen in (Figs. 12a, b, c, d, e, f, g, h, i, j) vs. (Figs. 11a, b, c, d).

\section{DISCUSSION}

All these findings are in line with those of the following studies:

Baculovirus inhibits the process of molting and causes the weak expression of the ecdysteroid UDP (Uridine diphosphate) glucosyltransferase gene that encodes the ecdysteroid UDPglucosyltransferase enzyme that induces the transfer of UDP-glucose to ecdysteroids, the insect molting hormone (O'Reilly,1995).

The histological investigation of Zethenia rufescentaria Motsch larvae after infection by $Z r N P V$ under optical and electron microscopes indicated that $Z r N P V$ destroyed fat bodies, epidermis cells, tracheal matrix, midgut cells, and, blood cells. These cells indicate major cytopathic effects, and their nuclei were fulfilled with NPV viral particles and were swollen (Daibin et al., 1999).

The midgut epithelial cells of Diaphania pulverulentalis Nuclear Polyhedrosis Virus $(D p N P V)$-infected larvae had irregularly shaped hypertrophied nuclei filled with large numbers of polyhedral bodies compared to normal nuclei. (Deng et al., 1991; Yan et al., 1991; Yu et al., 1993; Sanjaya et al., 2010). ZrNPV had a strong efficacy indoors and in the field in rapidly causing viral epidemic disease among insect hosts in a large area of the forest (Daibin et al., 1999). $Z r N P V$ could also infect the muscular sheath, nerve sheath, and pericardial cells (Huang 1987; Zhang 1988).

The histological and ultrastructure investigations of the Nuclear Polyhedrosis Virus- infected webbing clothes moth (Tineolabis selliella) under the electron microscope showed that NPV Polyhedra replicated in the nuclei of the cells of the foregut, midgut, hindgut, cardiac valve, pyloric valve, Malpighian tubules, muscle, ganglia of the ventral nerve cord, fat bodies, tracheae, and hypodermis. Also, virions are transported from the gut lumen in vesicles through the cytoplasm into the nuclei of columnar cells, and then they take a part of the membrane to be occluded in a polyhedral protein (Hunter et al., 1973). 
The histopathology of the Nuclear Polyhedrosis Virus-infected Almond Moth (Cadra cautella) indicated that NPV replication was primarily and mainly in the nuclei of the hypodermis, fat body, tracheal matrix, blood cells, Malpighian tubules, the epithelial \& connective tissues, the nervous system, the reproductive organs, muscles, and the frontal midgut cells that secret the peritrophic membrane (Jean et al., 1968).

Histopathological studies of the Diaphania pulverulentalis Nuclear Polyhedrosis Virus $(D p N P V)$-infected larvae revealed more infection with $N P V$ in the midgut, which was distinguished by the hypertrophy of nuclei filled with virions causing the death of leaf Webber larvae. Due to $D p N P V$ - restricted host specificity and non-toxicity to beneficial insects, it could be used as a safe biopesticide for the management of leaf Webber in the mulberry ecosystem (Pachiappan et al., 2018).

While there are few studies by other authors on the virus experimenting on coleopteran insects such as (Alois, 2005) who studied the effect of the Oryctes virus on Oryctes rhinoceros (Coleoptera: Scarabaeidae). This isolated virus was the first non-occluded, rod-shaped insect virus that resembled the baculoviruses morphologically. He studied the virulence and histopathology of this virus, confirming that it was infectious to larvae by oral application; therefore, massive disintegration and vacuoles of fat body tissue of a virus-infected third instar larva were observed.

Insects that are killed by baculoviruses are shiny-oily colored and crawl to the plant top where they die and decompose. The infected larvae are liquefied and rupture, releasing infective viral particles (Ramanujam et al., 2014; Devi et al., 2016). Also, there are many distinguishing symptoms such as sluggishness, skin discoloration, regurgitation of fluids, wet droppings, and larvae hanging upside down in the top of the plant, which is known as tree top disease (Sharma and Srivastava, 2013; Devi et al., 2016). Other insects can be infected by eating contaminated foliage with virus-ruptured larvae (Ramanujam et al., 2014).

\section{CONCLUSION}

Strawberry is an economically important plant in Egypt. The white grub, Pentodon algerinum (Coleoptera: Scarabaeidae) is a dangerous worldwide pest of several important plants (recently including strawberry in Egypt) and has caused massive destruction of the crop. This study aimed to distinguish, for the first time, the histopathological and morphological effects of Spodoptera littoralis Nuclear polyhedrosis virus (SpliNPV) and Pentodon algerinum Nuclear polyhedrosis virus (PNPV) on Pentodon algerinum third instar larvae to confirm their success as eco-friendly safe alternative biological control agents against Pentodon algerinum. The results confirmed that $P N P V$ and SpliNPV were effective against the Pentodon larva and caused various physiological changes disrupting its normal functions, leading to the collapse of its population. $P N P V$ and SpliNPV are not harmful to humans and other animals and are also host-specific; therefore, they can be recommended as eco-friendly safe alternative biological control agents against Pentodon algerinum.

\section{REFERENCES}

1. Abd El-Salam, A.M.E., Salem, H.A., Salem, S.A., 2013. Biocontrol agents against the leaf miner, Liriomyza trifolii in Faba bean fields. Arch. Phytopathol. Plant Prot. 46, 1054-1060. https://doi.org/10.1080/03235408.2012.7578 57.

2. Abd El-Salam, A.M.E., 2019. Field evaluation of some eco-friendly formulations against strawberry white grubs in Egypt. SCI Spec. J. Biol. Sci. 5, 1-6.

3. Abid, A.D., Saeed, S., Zaka, S.M., Ali, M., Shahzad, M.S., Khan, K.M., Iqbal, N., 2020a. Manifold passages in an assorted infection in a host could improve virulence of Helicoverpa armigera Nucleopolyhedrovirus (HaNPV). Saudi J. Biol. Sci. 27, 1419-1422. https://doi.org/10.1016/ j.sjbs.2020.02.023

4. Abid, A.D., Saeed, S., Zaka, S.M., Shahzad, S., Ali, M., Iqba, M., Iqba, N., Jamal, Z.A., $2020 b$. Field evaluation of nucleopolyhedrosis virus and some biorational insecticides against 
Helicoverpa armigera Hubner (Noctuidae: Lepidoptera). Saudi J. Biol. Sci. 27, 2106-2110.

https://doi.org/10.1016/j.sjbs.2020.06.025.

5. Alois M. Huger, 2005. The Oryctes virus: Its detection, identification, and implementation in biological control of the coconut palm rhinoceros beetle, Oryctes rhinoceros (Coleoptera: Scarabaeidae). J. Invertebr. Pathol. 89, 78-84. https://doi.org/ 10.1016/j.jip.2005.02.010.

6. Daibin, L., Wang, Z., Hua, Y., Hu, X., Huang, X., Xie, S., Liu, J., Luan, X., Mu, Z., 1999. Study on histopathology of nuclear polyhedrosis virus of Zethenia rufiscentaria Motsh. J. For. Res. 10, 51-54. https://doi.org/10.1007/BFo2855481.

7. Deng, R., Li, C., 1991. Pathological changes of blood cell of Procenia litura larvae infected by nuclear polyhedrosis virus. Insect-Kill Microorganism 3, 137-140.

8. Devi, E.B., Devi, E.P., Deepshikha, 2016. An overview on Nuclear Polyhedrosis Virus (NPV) as a valuable biopesticide in enhancing ecofriendly management of insect pests. Int. J. Curr. Res. Biosci. Plant Boil. 3, 97-106. http://dx.doi.org/10.20546/ijcrbp.2016.308.o 16.

9. Francesca, G., Josè, M.A.S., Luca, M., Stefania, R., Stefano, B., Jacopo, D., Franco, C., Bruno M., Josè, L.Q., Maria, S.F., Sara, T., Maurizio, B., 2012. The potential impact of strawberry on human health, Nat. Prod. Res. 27, 448-455. Formerly Natural Product Letters.https://doi.org/10.1080/14786419.20 12.706294 .

10. Food and Agriculture Organization of the United Nations (FAOSTAT). 2016.The International and Egyptian production of strawberries. Food and Agriculture Organization of the United Nations Statistics. (accessed on 23 July 2018) http:// faostat3.fao.org/

11. Food and Agriculture Organization of the United Nations.(FAOSTAT). 2021. Production of Strawberries: top 10 producers Average 2016-2019.https://www.tridge.com/intellige nces/stawberry/production (accessed on 18 March 2021).
12. Huang, J., 1987. Study on nuclear polyhedrosis virus of wavy marked caterpillar. For. Sci. 4, 443-447.

13. Hunter, D.K., Hoffmann, D.F., Collier, S.J., 1973. The histology and ultrastructure of a nuclear polyhedrosis virus of the webbing clothes moth, Tineolabiss elliella. J. Invertebr. Pathol. 21, 91-100.

14. Jean, R.A., Theodore, A.W., 1968. Histopathology of the Almond Moth, Cadra cautella, Infected with a Nuclear-Polyhedrosis Virus. J. Invertebr. Pathol. 12, 269-274. https://doi.org/10.1016/oo22-2011(68)90326 $-1$.

15. Masson, T., Fabre, M.L., Pidre, M.L., Niz, J.M., Berretta, M.F., Romanowski, V., Ferrelli, M.L., 2021. Genomic diversity in a population of Spodoptera frugiperda nucleopoly hedrovirus. Infect. Genet. Evol. 90, 104749. https://doi.org/10.1016/j.meegid.2021.10474

16. O’Reilly, D.R, 1995. Baculovirus - encoded ecdysteroid UDP glucosyl- transferases. Insect Biochem Mol Biol. 25, 541-550. https:// doi.org/10.1016/0965-1748(94)00105-Q.

17. Pachiappan, P., Prabhu, S., Mahalingam, C.A., 2018. Histopathological studies of mulberry leaf webber (Diaphania pulverulentalis) (Hampson) larva infected with nuclear polyhedrosis virus. J. Entomol. Zool. Stud. 6, 3002-3006

18. Parra JRP, 2014. Biological control in Brazil: an overview. Sci. Agric. 71, 420-429. http://dx.doi.org/10.1590/0103-9016-2014-O 167.

19. Prophet, E.B., Mills, B., Arrington, J.B. and Sobin, L.H, 1992. Laboratory methods in histotechnology, $1^{\text {st }}$ Edition. (Armed Forces Institute of Phatology). American Registry of Pathology, Washington.

20. Qayyum, M.A., Saleem, M.A., Saeed, S., Wakeel, W., Ishtiaq, M., Ashraf, W., Ahmed, N., Ali, M., Ikram, R.M., Yasin, M., Maqsood, S., Kiran, S., Qaiser, M.F., Ayaz, R.A., Nawaz, M.Z., Abid, A.D., Khan, K.A., Alamri, S.A., 2020. Integration of entomopathogenic fungi and eco-friendly insecticides for management of red palm weevil, Rhynchophorus ferrugineus (Olivier). Saudi J. Biol. Sci. 27, 
1811-1817.https://doi.org/10.1016/j.sjbs.2019 .12.018,

21. Ramadan, M. El-Ashry, Mahmoud, M. Ramadan, 2021. In vitro compatibility and combined efficacy of entomopathogenic nematodes with abamectin and imidacloprid against the white grub, Pentodon bispinosus Kust. Egypt. Acad. J. Biolog. Sci. (F. Toxicology \& Pest control), 13, 95-114. https://doi.org/10.21608/EAJBSF.2021.14581 7.

22. Ramanujam, B., Rangeshwaran, R., Sivakmar, G., Mohan, M., Yandigeri, M.S., 2014. Management of insect pests by microorganisms. Proc. Natl. Acad. Sci. India A. 8o, 455-471. http:// doi.org/10. 16943/ ptinsa/2014/v8oi2/3.

23. Salama, M.S., Abd El-Salam, A.M.E., Dalia, M. Mahmoud, Samah, M.M.A., 2017. Effect of Ultra violet radiations on insecticidal activity of Spodoptera littoralis Multinucleocapsid Nuclear Polyhedrosis Virus against Spodoptera littoralis Boisd (Lepidoptera: Noctuidae). Biosci. Res. 14, 645-652.

24. Samah, M.M. Abd EL-Aziz, Ahmed, M.E. Abd El-Salam, Mohammed, S. Salama, Dalia, M. Mahmoud, 2019. Effect of Ultraviolet radiation on original activity remaining of Spodoptera littoralis NPV against $S$. littoralis Boisd (Lepidoptera: Noctuidae). Egypt. J. Chem. 62, 173-178. https://doi.org/ 10.21608/EJCHEM .2019.12680.1786.

25. Samah, M.M. Abd El-Aziz, Magda, H. Rady, Bouthina, A. Merdan, Hany, M. Hussein, El-Sayed, M.A. El-Saiedy, Abd El-Salam, A.M.E., 2021. Nuclear polyhedrosis virus DNA identification and first evaluation against Strawberry pest, Pentodon algerinum (Coleoptera: Scarabaeidae). Egypt. J. Chem. 64,1239-1255.https://doi.org/10.21608/EJC HEM.2021.58765.3268.

26. Sanjaya, Y., Machmudin, D., Kurniawati, N.D., 2010. Histological study of SlNPV infection on body weight and peritrophic membrane damage of Spodoptera litura larvae. Bioscience 2, 135-140. https://doi.org/10. 13057/nusbiosci/no20305.
27. Sharma, N., Srivastava, R., 2013. In vitro production of nuclear polyhedrosis virus of Helicoverpa armigera. Persian Gulf crop protect., 2, 18-31.

28. Wilson, K., Grzywacz, D., Curcic, I., Scoates, F., Harper, K., Rice, A., Paul, N., Dillon, A., 2020. A novel formulation technology for baculoviruses protects biopesticide from degradation by ultraviolet radiation. Sci. Rep. 10, 13301. https://doi.org/10.1038 /s41598 -020-70293-7.

29. Yan, Z., Li, S., 1991. Study on the structure and tissue pathology of nuclear polyhedrosis virus of Dendrolimus spectabilis. Insect-Kill Microo- rganism, 3, 137-140.

30. Yasin, M., Muhammad, S.Q., Waqas, W., Mirza, A.Q., 2020. Evaluation of Nuclear Polyhedrosis Virus (NPV) and Emamectin Benzoate against Spodoptera litura (F.) (Lepidoptera: Noctuidae). Egypt. J. Biol. Pest Control. 30, 1-6. https://doi.org/10.1186/ s41938-020-00271-8

31. Yu, Z., Chen, Q., 1993. Observation of the blood cells of Laphyma exigua infected by two kinds of NPV. J. Huazhong Normal University $3,383-385$.

32. Zhang, L. 1988. The electron microscope atlas of insect viruses of China. Beijing: Science Press.

33. Zhao, M., Li, S., Zhou, Q., Zhou, D., He, N., Qian, Z. 2019. Safety evaluation of microbial pesticide (HaNPV) based on PCR method. Front. Chem. Sci. Eng. 13, 377-384. https://doi.org/10.1007/ s11705-018-1777-9. 
Figure legends

Figure 1 The histology of normal integument of $P$. algerinum larva

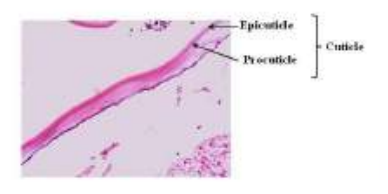

$\mathbf{a}$

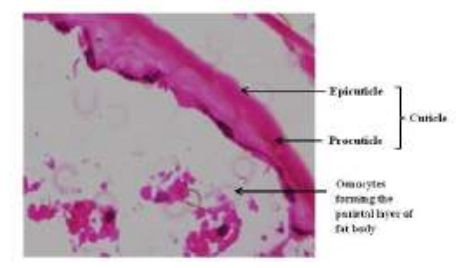

b

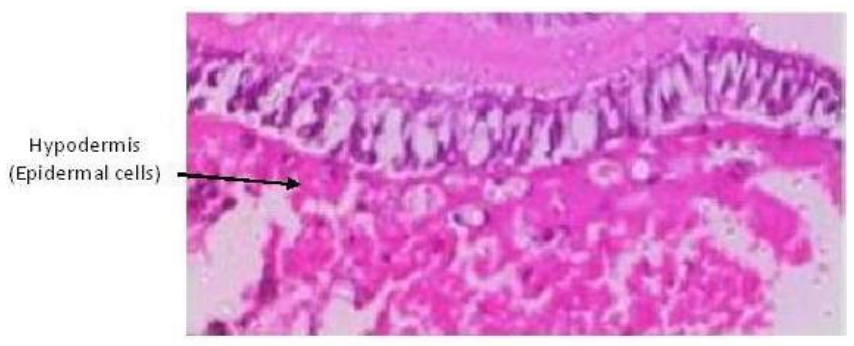

c

Figs. 1a, b, c: Longitudinal section of normal P. algerinum larvae showing a normal complete integument structure and a normal hypodermal layer (Magnification $=200,400 \times$ )

The normal integument is considered as a protective body covering, a surface for muscle attachment, a water-tight barrier against desiccation, and a sensory interface with the environment. It is a multi-layered structure with 3 important layers: The cuticle (consisting of an epicuticle (Cement, wax, polyphenol and, Cuticulin layers) \& procuticle (Exocuticle and Endocuticle)), hypodermis, and basement membrane.

Figure 2 The histopathology of the NPV-infected $P$. algerinum larval integument after infection

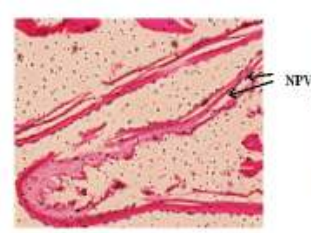

$\mathbf{a}$

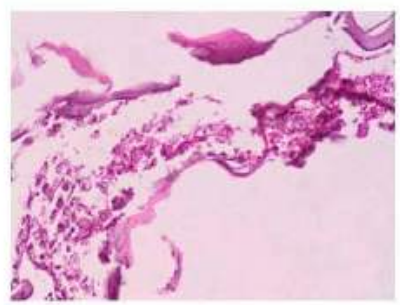

d

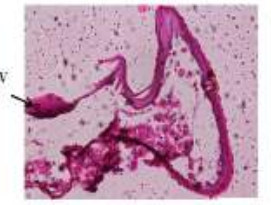

b

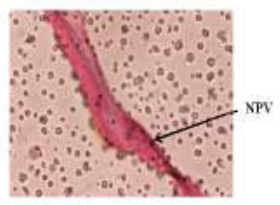

c

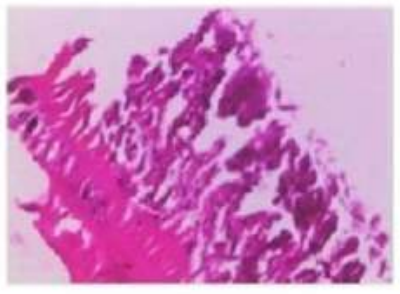

$\mathbf{e}$

Figs. 2a, $b, c, d$, e: Longitudinal section of the NPV-infected integument of the Pentodon larva showing NPV particles and the discontinuity of the cuticle layer with undistinguished hypodermal cells (Magnification $=200 \times$ ). 
Figure 3 The histology of normal fat bodies of P. algerinum larvae

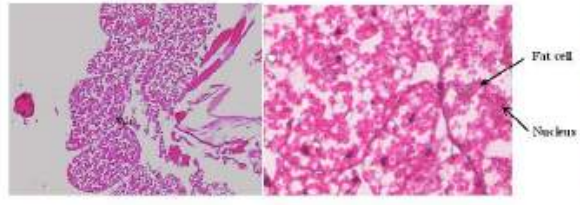

b

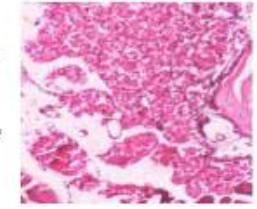

c $\mathbf{a}$

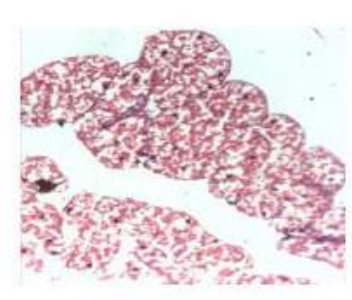

d

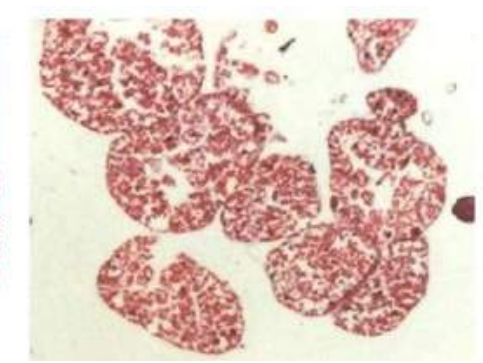

e

Figs. $3 a, b, c, d$, e: Longitudinal section of the normal $P$. algerinum larva showing normal fat bodies (Magnification $=(200,400 \times)$

The normal fat body consists of hexagonal contacted fat cells filled with storage materials. It has complete cells with a completed structure, nucleus, and complete cell sheath. The fat body is the tissue that occupies the spaces between the insect's organs. It is composed of cells of mesodermal origin and sometimes also contains ectodermic cells. It is identified as the perivascular layer, which is located around the organs, and the parietal layer, which is located adjacent to the integument. It is responsible for the storage of lipids, carbohydrates, and proteins, and for the synthesis of vitellogenins that are important for the insect's reproduction through their incorporation into the oocytes during vitellogenesis.

Figure 4 The histopathology of fat bodies of the Nuclear Polyhedrosis virus (NPV)-infected $P$. algerinum larva

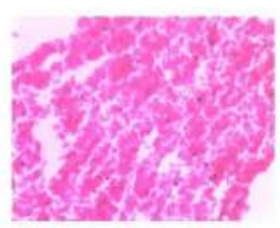

a

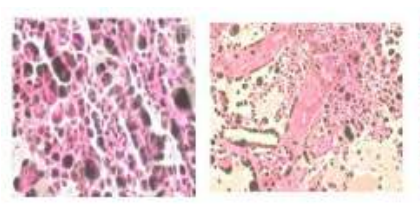

d

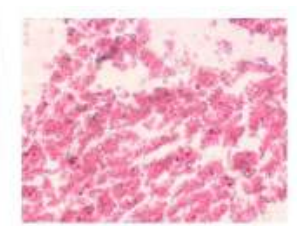

b

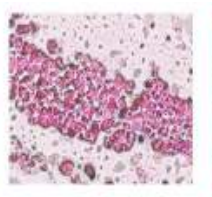

$\mathbf{f}$

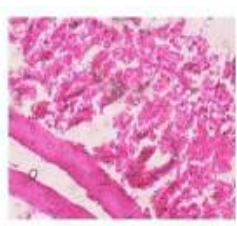

c

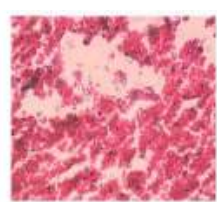

g

Figs. 4a, b, c, d, e, f, g: Longitudinal section of NPV-infected Pentodon larva fat bodies 
NPV-infected fat bodies lose both adipocytes and the fusion of lobules. The lobular architecture collapsed. They were filled with viral particles and had no waste granules. Also, there was the shrinkage of the fat bodies with vacuoles between cells with unclear nuclei and the rupture of the cell sheath. Hence, energy reserves were lost. (Magnification $=200,400 \times$ ).

Figure 5 The histology of the normal muscular system of the Pentodon larva

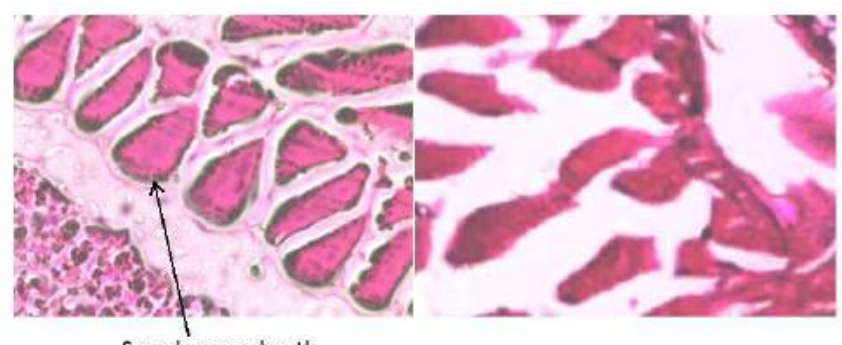

Sarcolemma sheath

a

b

Figs. 5a, b: Longitudinal section of a normal $P$. algerinum larva showing normal muscles

$($ Magnification $=400 \times)$

Normal muscle consists of many long fibers being compacted and surrounded by the sarcolemma membrane. A muscle fiber is composed of many fibrils, which gives the cell its striated form. Each fibril is subdivided into separate, smaller fibrils formed from a greatly organized array of myofilaments made up of actin \& myosin and alternating isotropic and anisotropic regions looking like light and dark bands or disks under the microscope.

Figure 6 The histopathology of muscles of the $N P V$-infected $P$. algerinum larva

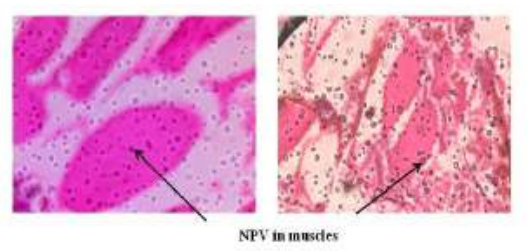

b

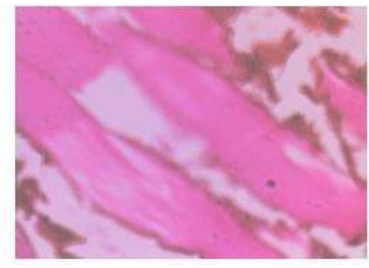

d

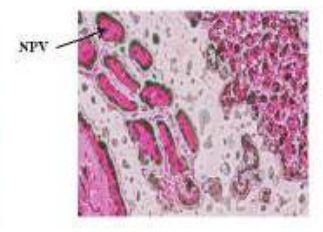

c

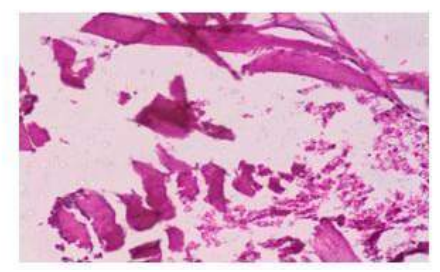

$\mathbf{e}$

Figs. 6a, b, $c, d$, e: Longitudinal section of the NPV-infected Pentodon larva muscles (Magnification = $200,400 \times)$

NPV-infected larval muscles were filled with NPV and appeared with irregular shapes of the sarcolemma with a fissured appearance; also, the fibers are distorted and not compacted. 
Figure 7 The histology of the normal tracheal matrix of the $P$. algerinum larva

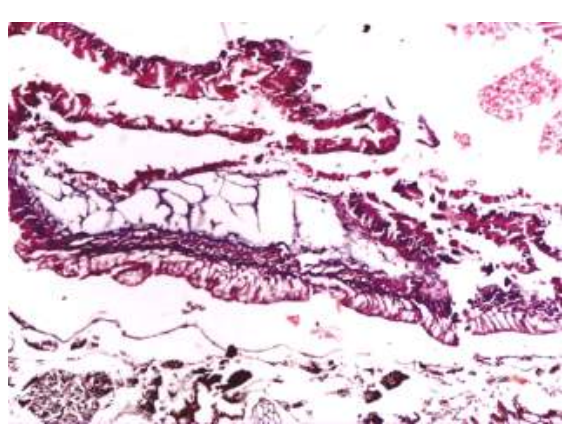

$\mathbf{a}$

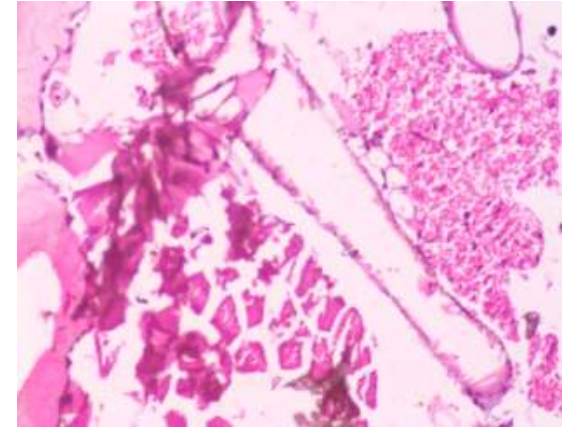

b

Figs. 7a, b: Longitudinal section of the normal $P$. algerinum larva's trachea (tracheal matrix) (Magnification $=200,400 \times)$.

The tracheal system is responsible for transporting sufficient oxygen $\left(\mathrm{O}_{2}\right)$ to all body cells and for removing carbon dioxide $\left(\mathrm{CO}_{2}\right)$ produced as a waste product of cellular respiration. Histologically, the trachea (tracheal matrix) comprises a cuticle layer, the epidermis, and a basement membrane, all of which are directly continuous with similar layers forming the general body wall. All or most of the cuticular lining of the trachea-spiracle system is usually shed during ecdysis. The P. algerinum larva has a peripneustic respiratory system with spiracles in a row along each side of the body.

Figure 8 The histopathology of the NPV-infected tracheal matrix of the P. algerinum larva.

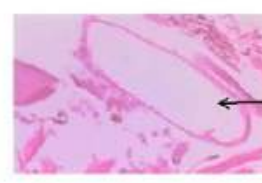

$\mathbf{a}$

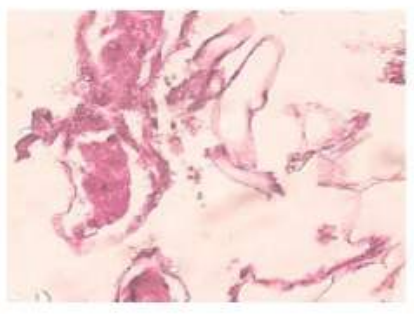

c

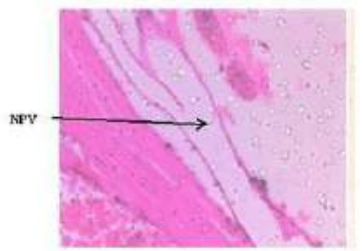

b

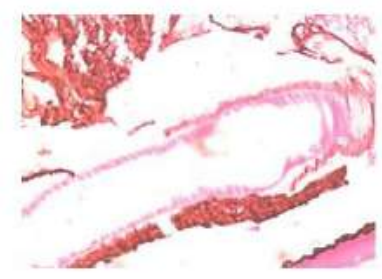

d

Figs. $8 a, b, c, d$ : Longitudinal section of the NPV-infected Pentodon larva's tracheal matrix with a crushed cuticular layer surrounded by acute necrosis. (Magnification $=200,400 \times$ )

There was the destruction of the cuticular layer of the trachea filled with the Nuclear Polyhedrosis virus (NPV). 
Figure 9 The histology of the normal midgut of the P. algerinum larva

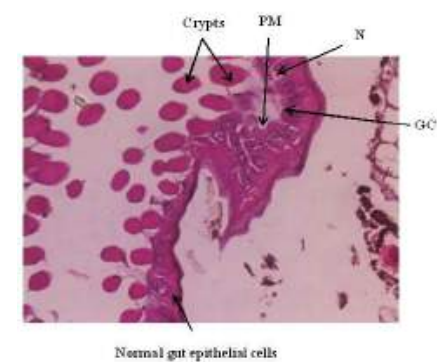

$\mathbf{a}$

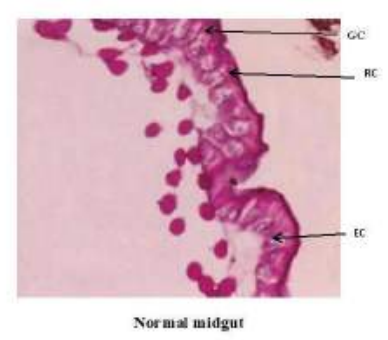

b

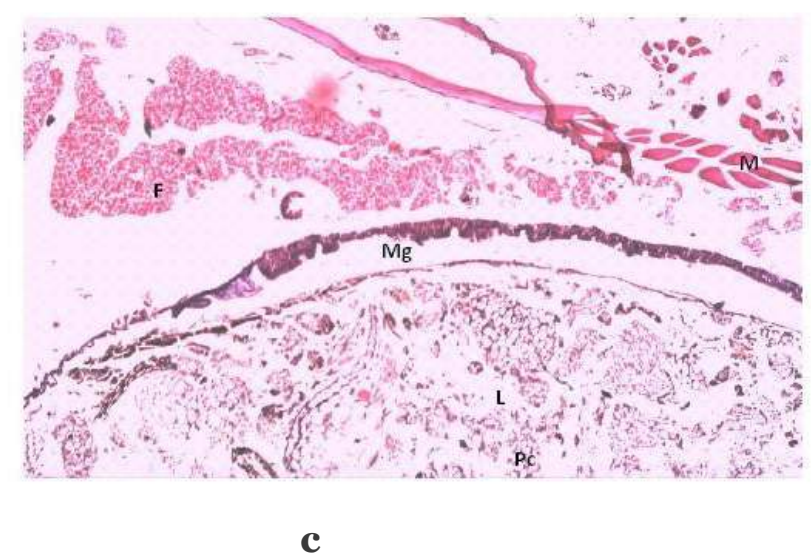

Figs. 9a, b: Longitudinal section in the normal Pentodon larva (Magnification $=400 \times$ ) showing the normal midgut region. $\mathrm{GC}=$ goblet cells, $\mathrm{N}=$ Nucleus, $\mathrm{PM}=$ Peritrophic membrane, $\mathrm{Rc}=$ Regenerative cells, $\mathrm{EC}=$ Epithelial cells

Fig. 9c: Transverse section of the normal Pentodon larva showing: $\mathrm{F}=$ fat bodies, $\mathrm{M}=\mathrm{Muscles,} \mathrm{Mg}=$ Midgut, $\mathrm{L}=$ Lumen of the midgut filled with $(\mathrm{Pc}=$ plant cells food) (Magnification $=100 \times$ ).

The normal midgut appeared with the complete shape. The normal epithelial cells appeared with a homogenous cytoplasm and a basic nucleus. The cells are attached and folded to form crypts. Goblet cells (Gc) and regenerative cells (Rc) were also observed.

Figure 10 The histopathology of the NPV-infected $P$. algerinum larval midgut

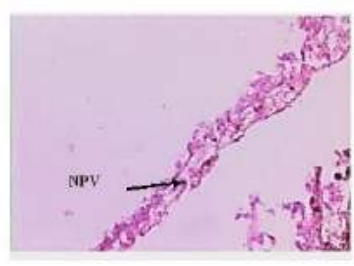

$\mathbf{a}$

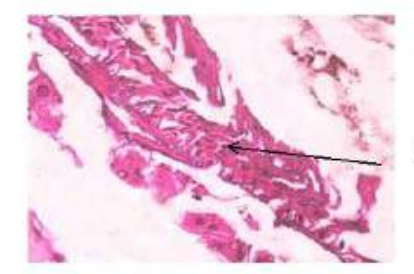

c

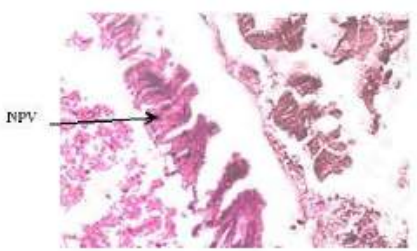

b

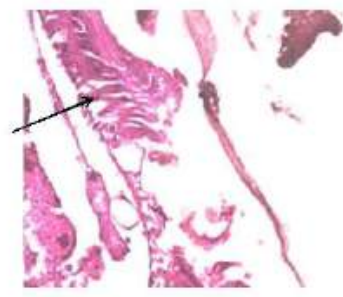

d 
Figs10a, b, c, d: Longitudinal section of the NPV-infected Pentodon larva (Magnification $=200 \times$ ) show the NPV-infected destroyed midgut of the Pentodon larva and no distinguishing of any cells in the NPV-infected gut region, a detachment of cells from each other, unformed distribution of the cytoplasm, cells losing their columnar shape, and the appearance of vacuoles between cells. (Magnification $=200 \times$ ).

Figure 11 The morphological investigation figures Normal Pentodon algerinum stages

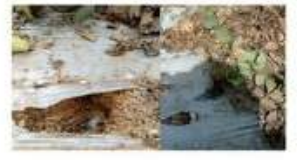

$\mathbf{a}$
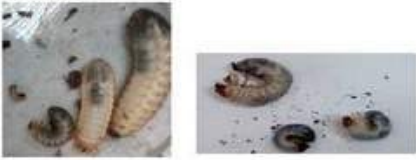

b

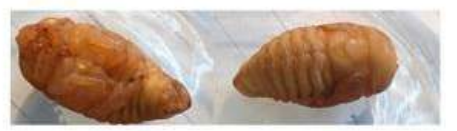

c

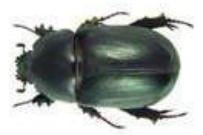

d

Fig. 11 a: Normal P. algerinum larvae under the plant root, Fig. 11b: Normal Pentodon larval instars

Fig. 11C: Normal Pentodon pupa, Fig. 11d: Normal Pentodon adult

Figs. 11a, b, c, d: Normal Pentodon algerinum stages

Figure 12 The morphological Symptoms of $P N P V$ and SpliNPV-infected dead $P$. algerinum larvae

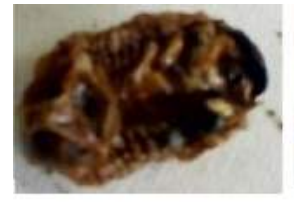

$\mathbf{a}$

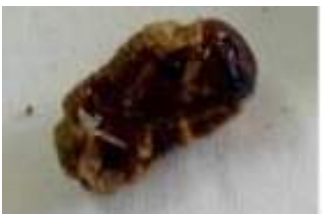

d

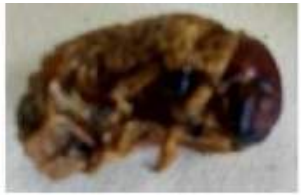

b

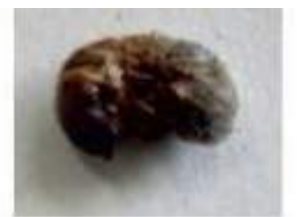

e

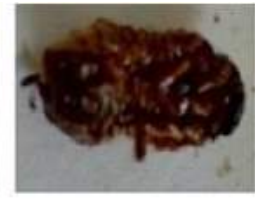

c

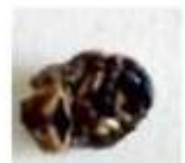

f

Dryness, weakness, leg corrosion, and death

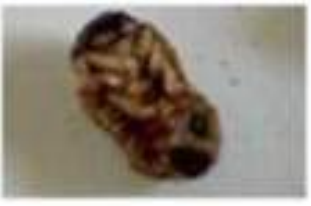

g

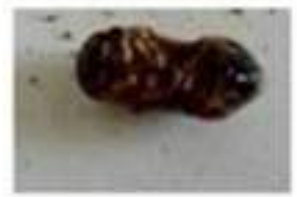

h

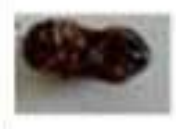

i

Dryness, weakness, and death 


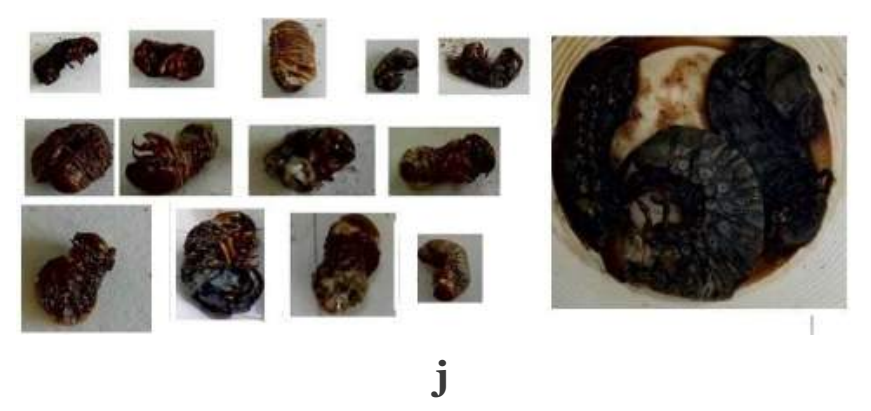

Figs. 12a, b, c, d, e, f, g, h, i, j: Morphological symptoms of PNPV and SpliNPV-infected dead $P$. algerinum larvae

These images show that PNPV and SpliNPV caused the same symptoms in the larvae, including the corrosion of the larva legs, which decreases its spreading and, also caused dryness, weakness, swelling, softness, liquefaction, bursting, and, finally, the death of these larvae. Also, the process of molting to the pupa stage was inhibited, leading to an interruption of the life cycle of this pest, which results in pest survival reduction. 